\title{
Cigarette smoking gives more respiratory symptoms among women than among men The Nord-Trøndelag Health Study (HUNT)
}

\author{
Arnulf Langhammer, Roar Johnsen, Jostein Holmen, A Gulsvik, L Bjermer
}

\begin{abstract}
Study objective-Studies have indicated that women are more vulnerable to the effect of tobacco smoking compared with men. The aim of this study was to explore the prevalence of reported respiratory symptoms and diseases according to smoking burden, age and sex.

Design-Questionnaire in a cross sectional population based study.

Setting-The BONT (Bronchial obstruction in Nord-Trøndelag) study is part of a comprehensive health survey of all inhabitants aged above 19 years in the county of Nord-Trøndelag, Norway, which was carried out from 1995 to 1997.

Participants-A total of 65717 subjects, $71.3 \%$ of the total population aged $20-100$, answered the main questionnaire.

Main results-In all, $12.7 \%$ men and $12.1 \%$ women reported episodes of wheezing or breathlessness during the past 12 months, $8.8 \%$ men and $8.4 \%$ women reported that they had or had had asthma, $7.5 \%$ men and $8.2 \%$ women had ever used asthma medication, and $4.0 \%$ men and $3.0 \%$ women reported chronic bronchitis. Thirty per cent of men and $31 \%$ of women were smokers, and average pack years of smoking were 15.9 and 10.3 , respectively. Among previous and current smokers, significant more women reported episodes of wheezing or breathlessness, current asthma and persistent coughing compared with men with the same smoke burden (pack years) and daily number of cigarettes.

Conclusion-The prevalence of reported asthma and use of asthma medication was higher than reported in previous Scandinavian studies. Respiratory symptoms increased by smoking burden. Comparing the prevalence of symptoms and current asthma among women and men with the same smoke burden or daily cigarette consumption, women seemed to be more susceptible to the effect of tobacco smoking than men.

(F Epidemiol Community Health 2000;54:917-922)
\end{abstract}

Respiratory symptoms vary by sex, smoking habits and age. There is increasing evidence of higher susceptibility in women to tobacco smoking compared with men. ${ }^{1}$ Studies indicate that women have increased smoking related bronchial responsiveness, lower level and faster decline of FEV1, and higher prevalence of asthma compared with smoking men. ${ }^{2-6}$ Studies from Copenhagen showed greater impact of smoking on lung function and higher risk of being admitted to hospital for chronic obstructive pulmonary disease (COPD) in women than in men. ${ }^{78}$

The aim of this study was to estimate the prevalence of respiratory symptoms and diseases in a large adult population covering the age range from 20 to 100 years old by sex, age, current cigarette smoking habits and lifelong cigarette smoking burden.

\section{Methods}

From August 1995 to June 1997 all residents aged 20 years and more (92 000), of the NordTrøndelag County, Norway, were invited to participate in a health study (HUNT). The invitation included a comprehensive Questionnaire I with focus on health, diseases, symptoms and risk factors. At the screening further questionnaires with more disease specific questions were added.

STUDY AREA

Nord-Trøndelag County (22 $\left.463 \mathrm{~km}^{2}\right)$ is situated in the middle part of Norway. The county has mostly mild coastal climate, but also typical inland areas with cold dry winters. The total population in 1995 was 127000 residents, $97 \%$ being of white origin. The area is generally rural with a scattered population, but with several densely populated areas and small cities, the largest of which has 21000 residents. Fifteen per cent of men and $6 \%$ of women worked as farmers. Except for previous mining industry in the two smallest municipalities, there is hardly any industrial pollution in the county.

\section{QUESTIONNAIRES}

The questions related to respiratory illnesses, diseases and smoking habits are listed in the appendix. Subjects, who reported "ever asthma" (having had asthma at one time or another) and episodes of wheezing or breathlessness during the past 12 months, were defined as having current asthma. Chronic bronchitis was defined as coughing with phlegm in periods of at least three months during each of the past two years. ${ }^{9}$

The smoking status was classified as never smokers (never smoked daily), ex-smokers (ceased smoking one or more years earlier) and current smokers.

Pack years was calculated as number of years of smoking $\times$ number of cigarettes a day $/ 20$. 
Table 1 Mean age, body mass index, and number of pack years in ever smokers with standard deviation (SD), and smoking habits by sex and age groups. Nord-Trøndelag, Norway 1997

\begin{tabular}{|c|c|c|c|c|c|c|c|c|}
\hline & \multicolumn{2}{|c|}{ Age 20-44 years } & \multicolumn{2}{|c|}{ Age 45-69 years } & \multicolumn{2}{|c|}{ Age $70+$ years } & \multicolumn{2}{|l|}{ All } \\
\hline & Men & Women & Men & Women & Men & Women & $M e n$ & Women \\
\hline Number & 12602 & 14442 & 13119 & 14074 & 5022 & 6458 & 30743 & 34974 \\
\hline Age & $33.4(7.0)$ & $33.1(7.1)$ & $55.6(7.3)$ & $55.8(7.3)$ & $76.5(5.7)$ & $77.3(5.5)$ & $50.0(17.0)$ & $50.4(17.8)$ \\
\hline Body mass index $\left(\mathrm{kg} / \mathrm{m}^{2}\right)$ & $25.9(3.5)$ & $25.0(4.3)$ & $27.0(3.4)$ & $26.9(4.6)$ & $26.5(3.5)$ & $27.6(4.6)$ & $26.5(3.5)$ & $26.3(4.6)$ \\
\hline Number of pack years in ever smokers & $9.3(7.7)$ & $7.2(5.9)$ & $19.0(14.4)$ & $13.2(9.9)$ & $21.9(17.0)$ & $12.8(10.9)$ & $16.0(13.9)$ & $10.3(4.6)$ \\
\hline \multicolumn{9}{|l|}{ Smoking habits ${ }^{\star}$} \\
\hline Never smoker & 6444 & 6404 & 3700 & 5810 & 1058 & 3908 & 11202 & 16122 \\
\hline Ex-smoker & 2016 & 2449 & 4872 & 3139 & 2468 & 804 & 9356 & 6392 \\
\hline Current smoker & 3539 & 4977 & 4079 & 4338 & 1057 & 619 & 8675 & 9934 \\
\hline
\end{tabular}

^1510 men and 2526 women had missing data on smoking habits.

NON-RESPONDER STUDY

In a non-responder study, $2.5 \%$ of the non-responders (685 persons) were randomly selected for a telephone interview with the same questions as in the survey. If no telephone contact was established after three attempts made for each subject on various occasions, a questionnaire was mailed to the subjects.

\section{STATISTICAL ANALYSIS}

Statistical Package for the Social Sciences version 8.0 (SPSS Inc, Chicago, Illinois) was used for all analyses. Differences between continuous variables were analysed by Student's $t$ test and dichotomous variables by the $\chi^{2}$ test. The Mantel-Haenszel method was used to analyse significance of trends. Body mass index (BMI, $\mathrm{kg} / \mathrm{m}^{2}$ ) has been reported to be an independent risk factor for onset of asthma in adult women${ }^{6}{ }^{10}$ and was therefore included in the analyses. Analyses of covariance were used to calculate prevalence adjusted for covariates as age, pack years and BMI. Sex specific risk of reporting respiratory diseases and symptoms by smoke exposure were calculated by multiple logistic regression with age, BMI, pack years or number of daily cigarettes in current smokers in the model. When education and different work categories were included in the model, education did not contribute significantly to the explained variance, but some work categories did. They did not, however, in the saturated model change the $\beta$ estimates significantly for BMI or pack years, and were therefore not included in the final model (table 3). Interaction of sex and pack years was used to test sex dependent susceptibility to smoke burden. The direct method of standardisation ${ }^{11}$ was used in age adjustment of prevalence in the non-responder group.

ETHICS

The study was approved by the Regional Committee for Ethics in Medical Research and the Norwegian Data Inspectorate.

\section{Results}

ATTENDANCE

A total of $73.9 \%$ women and $65.6 \%$ men completed the main questionnaire (total $71.3 \%$ ) (table 1). The response rates were $48.9 \%$ (20-29 years), 69.7\% (30-39 years), 80.6\% (40-69 years), $76.6 \%$ (70-79 years) and 51\% $(80+$ years $)$.
Table 2 Prevalence (\%) of self reported asthma, use of asthma medication, coughing and smoking status in responders $(n=65717)$ and in non-responders $(n=326)$. Nord-Trøndelag, Norway 1997

\begin{tabular}{lrcl}
\hline $\begin{array}{l}\text { Self reported symptoms } \\
\text { and smoking habits }\end{array}$ & $\begin{array}{l}\text { Responders } \\
\text { (\%) }\end{array}$ & $\begin{array}{l}\text { Non-responders } \\
\text { (\%) }\end{array}$ & p Value \\
\hline Ever asthma & 8.6 & 9.1 & 0.79 \\
Asthma medication & 8.0 & 9.5 & 0.52 \\
Coughing & 14.9 & 10.8 & 0.04 \\
Coughing with phlegm & 8.3 & 6.2 & 0.08 \\
Chronic bronchitis & 3.5 & 3.0 & 0.74 \\
Never smoker & 44.3 & 39.7 & 0.10 \\
Ex-smoker & 25.5 & 24.8 & 0.78 \\
Current smoker & 30.2 & 35.5 & 0.04 \\
\hline
\end{tabular}

Prevalence in non-responders age adjusted by direct method standardisation (total study population as reference).

NON-RESPONDER STUDY

Of 685 subjects randomly selected to the nonresponder study, 326 subjects (47.6\%) responded either to a telephone interview or the questionnaire. The most important reason for non-attending in age group 20-69 was lack of time/moved away (54\%), while in those aged 70 years or more immobilising disease (21\%) and follow up by medical doctor (28\%) were important reasons.

The only significant difference in reported symptoms and diseases was lower prevalence of coughing in non-responders compared with responders, even though a significant higher prevalence of smoking was found in the non-responder group (table 2).

\section{SMOKING HABITS}

A total of $29.7 \%$ of men and $30.6 \%$ of women reported current smoking, while $32 \%$ of men and $19.7 \%$ of women were ex-smokers (table 1). In age group 20-59 years smoking was more prevalent in women than in men $35.8 \%$ versus $31.0 \%, \mathrm{p}<0.001$ ), in contrast with subjects aged 60 or more (18.4\% versus $26.5 \%$ in women and men respectively, $\mathrm{p}<0.001)$. On average men started to smoke at younger age than women ( 18.4 versus 19.8 years, $\mathrm{p}<0.001$ ), and had higher average daily cigarette consumption (13.1 versus 9.7 cigarettes, $\mathrm{p}<0.001)$. In "ever smokers" the average number of pack years were 16.0 and 10.3 for men and women respectively $(\mathrm{p}<0.001)$.

SYMPTOMS AND RESPIRATORY DISEASE Episodes of wheezing or breathlessness In all, $12.7 \%$ of men and $12.1 \%$ of women reported episodes of wheezing or breathlessness during the past 12 months. Smokers reported these symptoms twice as prevalent as never smokers, and the prevalence increased by 
Table 3 Prevalence (\%) of self reported respiratory symptoms, asthma, chronic bronchitis and use of asthma medication in 34974 women and 30743 men by age groups and smoking habits, with 95\% confidence intervals. Nord-Trøndelag, Norway 1997

\begin{tabular}{|c|c|c|c|c|c|c|c|c|c|c|c|c|}
\hline & \multicolumn{4}{|c|}{ Age 20-44 years } & \multicolumn{4}{|c|}{ Age 45-69 years } & \multicolumn{4}{|c|}{ Age $70+$ years } \\
\hline & \multicolumn{2}{|l|}{ Men } & \multicolumn{2}{|c|}{ Women } & \multicolumn{2}{|l|}{ Men } & \multicolumn{2}{|c|}{ Women } & \multicolumn{2}{|l|}{ Men } & \multicolumn{2}{|c|}{ Women } \\
\hline & $\%$ & $95 \% C I$ & $\%$ & $95 \% C I$ & $\%$ & $95 \% C I$ & $\%$ & $95 \% C I$ & $\%$ & $95 \% C I$ & $\%$ & $95 \% C I$ \\
\hline \multicolumn{13}{|c|}{ Wheezing/breathless } \\
\hline Never smoker & 7.9 & $7.2,8.6$ & 7.7 & $7.0,8.4$ & 7.6 & $6.7,8.5$ & 9.2 & $8.4,10.0$ & 11.4 & $9.5,13.3$ & 12.4 & $11.4,13.4$ \\
\hline Ex-smoker & 9.9 & $8.6,11.2$ & 9.8 & $8.6,11.0$ & 12.5 & $11.6,13.4$ & 12.2 & $11.0,13.4$ & 18.9 & $17.3,20.5$ & 18.0 & $15.3,20.7$ \\
\hline Smoker & 15.4 & $14.2,16.6$ & 15.9 & $14.9,16.9$ & 18.6 & $17.4,19.8$ & 17.7 & $16.6,18.8$ & 24.0 & $21.4,26.6$ & 20.7 & $17.5,23.9$ \\
\hline Total & 10.3 & $9.8,10.8$ & 10.9 & $10.4,11.4$ & 13.0 & $12.4,13.6$ & 12.7 & $12.1,13.3$ & 18.2 & $17.1,19.3$ & 13.9 & $13.0,14.8$ \\
\hline \multicolumn{13}{|l|}{ Ever asthma } \\
\hline Never smoker & 8.1 & $7.4,8.8$ & 7.7 & $7.0,8.4$ & 7.3 & $6.5,8.1$ & 6.8 & $6.2,7.4$ & 6.8 & $5.3,8.3$ & 7.6 & $6.8,8.4$ \\
\hline Ex-smoker & 9.8 & $8.5,11.1$ & 9.7 & $8.5,10.9$ & 9.3 & $8.5,10.1$ & 8.8 & $7.8,9.8$ & 12.2 & $10.9,13.5$ & 11.9 & $9.7,14.1$ \\
\hline Smoker & 8.3 & $7.4,9.2$ & 9.0 & $8.2,9.8$ & 8.4 & $7.5,9.3$ & 9.8 & $8.9,10.7$ & 11.2 & $9.3,13.1$ & 10.6 & $8.2,13.0$ \\
\hline Total & 8.5 & $8.0,9.0$ & 8.5 & $8.0,9.0$ & 8.4 & $7.9,8.9$ & 8.3 & $7.8,8.8$ & 10.7 & $9.8,11.6$ & 8.5 & $7.8,9.2$ \\
\hline \multicolumn{13}{|c|}{ Asthma medication } \\
\hline Never smoker & 7.3 & $6.7,7.9$ & 7.9 & $7.2,8.6$ & 5.6 & $4.9,6.3$ & 6.7 & $6.1,7.3$ & 5.9 & $4.5,7.3$ & 6.6 & $5.8,7.4$ \\
\hline Ex-smoker & 9.0 & $7.7,10.3$ & 9.3 & $8.1,10.5$ & 8.2 & $7.4,9.0$ & 9.0 & $8.0,10.0$ & 11.9 & $10.6,13.2$ & 12.4 & $10.1,14.7$ \\
\hline Smoker & 6.5 & $5.7,7.3$ & 9.5 & $8.7,10.3$ & 6.8 & $6.0,7.6$ & 9.3 & $8.4,10.2$ & 11.2 & $9.3,13.1$ & 9.4 & $7.1,11.7$ \\
\hline Total & 7.3 & $6.8,7.8$ & 8.7 & $8.2,9.2$ & 7.1 & $6.7,7.5$ & 8.1 & $7.6,8.6$ & 10.3 & $9.4,11.2$ & 7.6 & $6.9,8.3$ \\
\hline \multicolumn{13}{|c|}{ Daily coughing in periods } \\
\hline Never smoker & 9.8 & $9.1,10.5$ & 9.7 & $9.0,10.4$ & 10.8 & $9.8,11.8$ & 11.8 & $11.0,12.6$ & 11.5 & $9.6,13.4$ & 11.7 & $10.7,12.7$ \\
\hline Ex-smoker & 11.2 & $9.8,12.6$ & 9.8 & $8.6,11.0$ & 10.6 & $9.7,11.5$ & 11.7 & $10.6,12.8$ & 16.2 & $14.7,17.7$ & 14.7 & $12.2,17.2$ \\
\hline Smoker & 24.3 & $22.9,25.7$ & 23.2 & $22.0,24.4$ & 29.4 & $28.0,30.8$ & 23.4 & $22.1,24.7$ & 29.7 & $26.9,32.5$ & 21.6 & $18.4,24.8$ \\
\hline Total & 14.2 & $13.6,14.8$ & 14.4 & $13.8,15.0$ & 16.5 & $15.9,17.1$ & 15.3 & $14.7,15.9$ & 17.9 & $16.8,19.0$ & 13.0 & $12.2,13.8$ \\
\hline \multicolumn{13}{|c|}{ Coughing with phlegm } \\
\hline Never smoker & 4.9 & $4.4,5.5$ & 4.5 & $4.0,5.0$ & 5.3 & $4.6,6.0$ & 5.6 & $5.0,6.2$ & 7.2 & $5.6,8.8$ & 5.9 & $5.2,6.7$ \\
\hline Ex-smoker & 6.4 & $5.4,7.5$ & 4.5 & $3.7,5.4$ & 6.4 & $5.7,7.1$ & 5.9 & $5.1,6.8$ & 10.4 & $9.2,11.6$ & 9.5 & $7.5,11.5$ \\
\hline Smoker & 13.8 & $12.7,15.0$ & 13.1 & $12.2,14.1$ & 17.2 & $16.0,18.4$ & 13.0 & $12.0,14.0$ & 22.1 & $19.6,24.7$ & 14.3 & $11.5,17.0$ \\
\hline Total & 7.7 & $7.3,8.2$ & 7.6 & $7.1,8.0$ & 9.4 & $8.9,9.9$ & 8.0 & $7.5,8.4$ & 12.1 & $11.2,13.0$ & 7.2 & $6.6,7.9$ \\
\hline \multicolumn{13}{|c|}{ Chronic bronchitis } \\
\hline Never smoker & 1.4 & $1.1,1.7$ & 1.2 & $0.9,1.5$ & 2.3 & $1.8,2.8$ & 2.7 & $2.3,3.1$ & 2.6 & $1.6,3.5$ & 3.0 & $2.4,3.5$ \\
\hline Ex-smoker & 1.5 & $1.0,2.0$ & 1.4 & $1.0,1.9$ & 3.5 & $3.0,4.0$ & 2.8 & $2.2,3.4$ & 5.7 & $4.8,6.7$ & 5.0 & $3.5,6.5$ \\
\hline Smoker & 4.7 & $4.0,5.4$ & 3.8 & $3.3,4.4$ & 8.4 & $7.6,9.3$ & 5.5 & $4.8,6.2$ & 12.7 & $10.7,14.7$ & 7.3 & $5.3,9.4$ \\
\hline Total & 2.4 & $2.1,2.6$ & 2.2 & $1.9,2.4$ & 4.7 & $4.3,5.0$ & 3.7 & $3.3,4.0$ & 6.5 & $5.8,7.2$ & 3.6 & $3.1,4.1$ \\
\hline
\end{tabular}

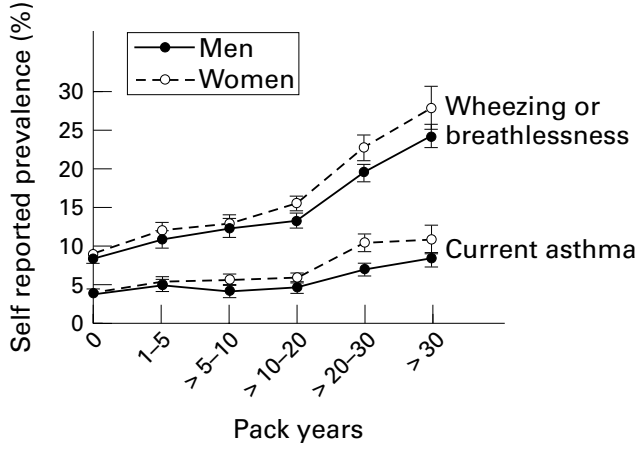

Figure 1 Age adjusted prevalence (\%) of self reported episodes of wheezing or breathlessness in the past 12 months and current asthma by number of pack years in men and women (95\% confidence intervals). Nord-Trøndelag,

Norway 1997.

smoking burden ( $\mathrm{p}$ for trend $<0.001$ ) (table 3, fig 1). Among never smokers more women than men $(9.2 \%$ versus $8.6 \%$ when adjusted by age and $\mathrm{BMI}, \mathrm{p}<0.001$ ), reported wheezing or breathlessness and the difference between sexes increased by increasing smoke burden (pack years) (table 4, fig 1 ).
Ever asthma and current asthma

Some $8.8 \%$ of men and $8.4 \%$ of women reported "ever asthma" (table 3), and $4.8 \%$ of men and $5.1 \%$ of women was categorised as having current asthma. The lowest cumulative prevalence of asthma was reported in the group aged $40-49(7.9 \%)$ as compared with the groups aged $20-29(9.3 \%, \mathrm{p}<0.001)$ and $70-79(9.6 \%, \mathrm{p}<0.001)$. In those reporting ever asthma, $97.5 \%$ of women and $96.9 \%$ of men reported that they had been given the diagnosis by a medical doctor.

"Ever smoking" women reported current asthma more frequently than "ever smoking" men $(6.4 \%$ versus $5.7 \%, \mathrm{p}=0.005)$. A similar pattern was also found among current smokers (fig 1). The prevalence of current asthma increased with increasing number of cigarettes per day in women, amounting to $10.4 \%$ in those smoking more than 20 cigarettes per day. In men, however, no such increase with increasing cigarette consumption was found. With increasing smoke burden and current smoker's daily cigarette consumption, more

Table 4 Multiple logistic regression of episodes of wheezing or breathlessness, current asthma, persistent coughing and chronic bronchitis in men $(n=26914)$ and women $(n=30809)$ by pack year adjusted by age and body mass index. Nord-Trøndelag, Norway 1997

\begin{tabular}{|c|c|c|c|c|c|c|c|c|}
\hline \multirow[b]{2}{*}{ Independent variables } & \multicolumn{2}{|c|}{$\begin{array}{l}\text { Wheezing or } \\
\text { breathlessness }\end{array}$} & \multicolumn{2}{|c|}{ Current asthma } & \multicolumn{2}{|c|}{ Persistent coughing } & \multicolumn{2}{|c|}{ Chronic bronchitis } \\
\hline & $O R$ & $95 \% C I$ & OR & $95 \% C I$ & $O R$ & $95 \% C I$ & $O R$ & $95 \% C I$ \\
\hline \multicolumn{9}{|l|}{ Men } \\
\hline Age (y) & 1.005 & $1.002,1.007$ & 1.008 & $1.004,1.012$ & 0.996 & $0.994,0.998$ & 1.022 & $1.017,1.026$ \\
\hline Body mass index $\left(\mathrm{kg} / \mathrm{m}^{2}\right)$ & 1.053 & $1.042,1.064$ & 1.050 & $1.034,1.066$ & 1.002 & $0.992,1.011$ & 0.982 & $0.964,1.001$ \\
\hline $\begin{array}{l}\text { Number of pack years } \\
\text { Women }\end{array}$ & 1.025 & $1.023,1.028$ & 1.015 & $1.011,1.018$ & 1.032 & $1.030,1.035$ & 1.015 & $1.011,1.020$ \\
\hline Age $(y)$ & 1.001 & $0.999,1.003$ & 0.998 & $0.995,1.001$ & 0.997 & $0.995,0.999$ & 1.010 & $1,006,1.014$ \\
\hline Body mass index $\left(\mathrm{kg} / \mathrm{m}^{2}\right)$ & 1.063 & $1.054,1.070$ & 1.062 & $1.051,1.073$ & 1.021 & $1.014,1.028$ & 1.025 & $1.011,1.040$ \\
\hline Number of pack years & 1.038 & $1.035,1.042$ & 1.030 & $1.025,1.035$ & 1.048 & $1.044,1.051$ & 1.030 & $1.023,1.036$ \\
\hline
\end{tabular}




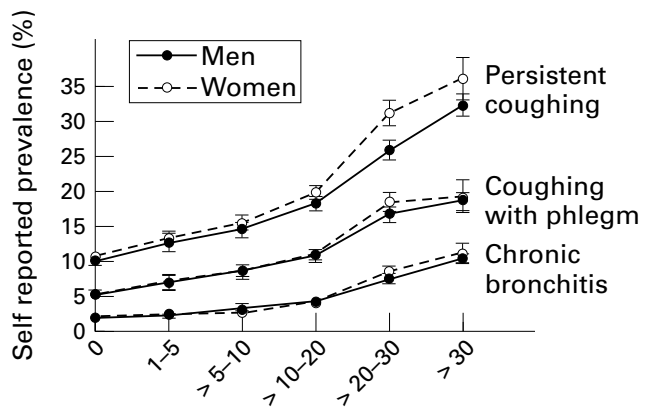

Pack years

Figure 2 Age adjusted prevalence of persistent coughing, coughing with phlegm and chronic bronchitis by number of pack years in men and women (95\% confidence intervals). Nord-Trøndelag, Norway 1997.

women than men reported current asthma (table 4, fig 1).

\section{Coughing, phlegm and chronic bronchitis}

Persistent coughing was reported more than twice among smokers compared with never smokers throughout all age groups except in the oldest group of women. Men reported higher crude prevalence than women did in all cough related questions. With increasing smoking burden and daily cigarette consumption the prevalence of coughing increased, and even for this symptom we found higher susceptibility in women compared with men (table 4, fig 2).

\section{SMOKING CESSATION IN RELATION TO SYMPTOMS} AND SEX

Among women who reported coughing, there was an increase of $40 \%$ that had quit smoking compared with those without symptoms (table 5). Among men, no such relation was seen. Among reporters of asthma related complaints, twice as many women and 1.7 as many men had quit smoking compared with those without respiratory symptoms. However, more "ever smoking" men than women had quit smoking, regardless of whether they reported respiratory symptoms at the screening or not. In subjects with current asthma $23.3 \%$ women and 39\% men were ex-smokers and $38.5 \%$ women and $32.8 \%$ men were current smokers.

\section{Discussion}

In this population based cross sectional study we found higher prevalence of self reported asthma and use of asthma medication than previous studies in eastern Norway, including the city of Oslo 1972, ${ }^{12}$ Northern Sweden

Table 5 Sex specific and age adjusted prevalence of self reported smoking cessation in ever smoking women (16 326) and men (18 031) according to symptoms, chronic bronchitis, asthma and use of asthma medication. (95\% confidence intervals). Nord-Trøndelag, Norway 1997

\begin{tabular}{llllll}
\hline & \multicolumn{2}{l}{ Women } & & \multicolumn{2}{l}{ Men } \\
\cline { 2 - 3 } \cline { 5 - 6 } Symptom/disease & $\%$ & $95 \% C I$ & & & \\
\hline No symptom & 19.3 & $18.8,19.8$ & & 32.0 & $31.4,32.5$ \\
Coughing in periods & 27.3 & $25.8,28.9$ & & 31.0 & $29.4,32.5$ \\
Coughing with phlegm & 25.8 & $23.7,28.0$ & & 31.3 & $29.3,33.4$ \\
Chronic bronchitis & 29.6 & $26.1,33.4$ & & 32.9 & $30.0,36.0$ \\
Wheezing or breathlessness & 35.2 & $33.2,37.2$ & & 43.2 & $41.4,45.0$ \\
Ever asthma & 42.7 & $40.3,45.2$ & & 54.5 & $52.1,56.8$ \\
Current asthma & 41.1 & $38.1,44.1$ & & 52.4 & $49.3,55.5$ \\
Use of asthma medication & 43.1 & $40.6,45.6$ & & 56.3 & $53.8,58.8$ \\
\hline
\end{tabular}

KEY POINTS

- Higher prevalence of reported asthma and use of asthma medication than reported in previous Scandinavian studies.

- The prevalence of respiratory symptoms increased by smoking burden (number of pack years).

- More women than men were current smokers.

- Women seemed to be more susceptible to the effect of tobacco smoking than men.

$1986,{ }^{13}$ Southern Sweden $1992^{14}$ and Denmark 1997. ${ }^{15}$ The reporting of "ever asthma", ever having used asthma medication and current asthma had the lowest prevalence in the middle aged group (40-49 years). There was a strong association between tobacco smoking and respiratory symptoms, and smokers reported symptoms more than twice as frequent compared with never smokers. With increasing smoking burden, more women reported symptoms such as episodes of wheezing or breathlessness, persistent coughing, in addition to current asthma than men did. In a cross sectional study, however, causation cannot be directly inferred.

The questions of asthma, asthma medication and coughing used in this study were similar to those used by others. ${ }^{16}{ }^{17}$ Unlike others, we combined the question of wheezing and breathlessness in one question, limiting the comparison of these symptoms with other studies.

PARTICIPANTS AND QUESTIONS

The participation rate was about $10 \%$ lower in all age groups compared with a similar health survey in $1984-86,{ }^{18}$ with lowest rates in younger age groups, especially among men. Some people are sceptical of such studies and actively choose not to participate. This could explain that only about $50 \%$ answered the non-responder study. Other reasons for nonattendants in this survey were time consuming examinations and absence from work. A high prevalence of smokers in non-responders or late responders compared with early responders is in accordance with other studies where smoking habits have been examined. ${ }^{18-20}$ Equal distributions of respiratory symptoms do not preclude non-responder bias, ${ }^{21}$ but we have no reason to believe that our study overestimates the prevalence of respiratory symptoms and diseases.

RESPIRATORY SYMPTOMS AND DISEASES BY SEX The study confirms a clear relation between tobacco smoking and respiratory symptoms like wheezing, breathlessness and coughing. ${ }^{22-25}$

More women reported respiratory symptoms compared with men in never smokers and smokers with comparable smoke burden or number of cigarettes. Generally, women seem to have lower threshold for reporting such symptoms compared with men. ${ }^{24}{ }^{26}$ It has however, been proposed that respiratory symptoms 
are more sensitive markers of change in general health, but less specific markers regarding respiratory diseases in women compared with men. ${ }^{1}$ This is confirmed by studies showing that respiratory symptom as shortness of breath is equally predictive of mortality in both sexes. ${ }^{27}{ }^{28}$ Although, this does not explain the increasing sex difference with increasing smoke burden.

Regarding coughing with phlegm, no sex difference by increasing smoke burden was reported. This symptom is probably underestimated in women as they are less likely to report phlegm than men. ${ }^{1}$

Higher prevalence of respiratory symptoms and current asthma in women compared with men with the same smoke burden or daily cigarette consumption indicate that women are more susceptible to tobacco smoking than men. Cyclical hormonal variations ${ }^{1}$ and possible anti-oestrogenic effect of smoking ${ }^{29}$ have been discussed as reasons. Given the same degree of inhalation per cigarette, female airways probably are exposed to higher relative concentration of gases and particles compared with men. In Copenhagen comparable sex difference in smoking effect was found both on lung function and risk of hospitalisation for patients with COPD. ${ }^{8}$ Higher prevalence of coughing as well as wheezing and breathlessness attributable to tobacco smoking in women than men could indicate future increase of COPD, especially among women.

DISEASE AND SYMPTOM PREVALENCE

There is a wide geographical variation in prevalence of asthma and use of asthma medication. ${ }^{30}$ The prevalence of self reported asthma and use of asthma medication was higher than found in earlier Scandinavian studies $^{12131531}$ and in crude agreement with more recent studies. ${ }^{14} 32$ This could reflect an increasing incidence of asthma, but also increased focus on asthma and asthma treatment in Norway. A high prevalence of asthma in the group aged 20-29, consistent with other studies, ${ }^{14}$ could support the hypothesis of increasing asthma incidence in younger age cohorts, but this is under debate. ${ }^{33}$

Lack of increase in prevalence of "ever asthma" or current asthma with age in never smokers, are in agreement with the ECHRS study ${ }^{30}$ and a study from Southern Sweden. ${ }^{14}$ In a chronic disease like asthma, one could expect increase in cumulative prevalence. The absence of this age effect could partly be explained by increasing recall bias with age, low symptom perception, and under-diagnosis of asthma in elderly. ${ }^{34}$ A change of diagnostic criteria during the past decades could also mask an increasing prevalence with age.

SMOKING AND SMOKING CESSATION

According to the WHO the overall smoking prevalence in Norway is $35.5 \%$ in women and $36.4 \%$ in men, and only Danish women have higher proportion of smoking than Norwegian women have. Norwegian men are ranked 62 in the world. ${ }^{36}$ We found that men reported smoking cessation more frequently than women did, regardless of reporting respiratory symptoms at the screening or not.

Even though women feel more pressure from family and society to quit smoking, and are equally likely to quit smoking compared with men, they are less likely to remain abstinent than men are. One important problem in motivating women to cease smoking is that they more probably view weight control as a benefit of smoking. ${ }^{37-39}$

A higher prevalence of asthma among ex-smokers compared with smokers have been found in several studies. ${ }^{40}{ }^{41}$ We confirmed this among men, but not among women. There was a similar sex difference in reported use of asthma medication. These findings might support the view that mostly men without asthmalike symptoms go on smoking (the healthy smoker effect). ${ }^{42}$ A previous study has indicated a higher tendency for smoking men to be given the diagnosis of chronic obstructive lung disease compared with women. ${ }^{43}$ This study could not identify differences in use of diagnosis as chronic bronchitis and asthma between the sexes.

In conclusion, the respiratory symptoms were clearly associated with tobacco smoking. At the same smoking burden, more women reported respiratory symptoms and current asthma than men did. Even if symptoms seemed to motivate more women than men to cease smoking, more men had quit smoking regardless of whether they had or did not have respiratory symptoms. High prevalence of smoking in young women combined with a possible increased susceptibility to tobacco smoking compared with men, might contribute to future increase in serious smoke related diseases in Norwegian women. To prevent this scenario it is necessary to develop programmes that encourage non-smoking in adolescents and effectively aid adults in ceasing to smoke. Different strategies seem to be necessary for men and women. ${ }^{44}$

The Nord-Trøndelag Health Study 1995-97 (The HUNT study) was performed in collaboration between The National Institute of Public Health, Oslo, The National Health Screening Service, Oslo, The Norwegian University of Technology and Science, Trondheim and Nord-Trøndelag County Council.

Funding: The Bronchial Obstruction in Nord-Trøndelag (The BONT study) was funded by Astra Norway.

Conflicts of interest: none.

\section{Appendix}

Questions regarding respiratory symptoms and diseases: (in parentheses the questions as given in tables and text).

\section{QUESTIONNAIRE I}

1 Do you cough daily during periods of the year? (persistent coughing)

If Yes:

Do you usually bring up pleghm when coughing? (coughing with phlegm)

Have you had cough with phlegm for periods of at least three months during each of the past two years? (chronic bronchitis)

2 Have you had any attack of wheezing or breathlessness during the past 12 months? (wheezing or breathlessness past 12 months) 
3 Do you have or have you had asthma? (ever asthma)

4 Do you use or have you used asthma medication? (ever use of asthma medications)

5 Do you smoke?

Cigarettes daily?

Cigars/cigarillos daily?

Pipe daily?

Never smoked daily

6 If you have smoked earlier; how many years is it since you stopped?

7 If you smoke daily now or have smoked earlier:

How many cigarettes do you smoke or did you smoke usually per day?

How old were you when you started smoking?

How many years altogether have you smoked?

QUESTIONNAIRE II

1 Have you been diagnosed as having asthma by your doctor?

2 Have you been diagnosed as having chronic bronchitis or emphysema by your doctor?

1 Kauffmann F, Becklake MR, Saurel-Cubizolles M-J, et al. La santé des femmes. Paris: Médecine-Sciences, Flammarion, 1996:209-33

$2 \mathrm{Xu}$ X, Dockery DW, Ware JH, et al. Effects of cigarette smoking on rate of loss of pulmonary function in adults: a longitudinal assessment. Am Rev Respir Dis 1992;146: $1345-8$.

3 Xu X, Weiss ST, Rijcken B, et al. Smoking, changes in smoking habits, and rate of decline in FEV1: new insight into gender differences. Eur Respir F 1994;7:1056-61.

$4 \mathrm{Xu} \mathrm{X}, \mathrm{Li} \mathrm{B}$, Wang L. Gender difference in smoking effects on adult pulmonary function. Eur Respir F 1994;7:477-83.

5 Gold DR, Wang X, Wypij D, et al. Effects of cigarette smoking on lung function in adolescent boys and girls. $N$ Engl $\mathcal{F}$ Med 1996;335:931-7.

6 Chen Y, Dales R, Krewski D, et al. Increased effects of smoking and obesity on asthma among female Canadians: the National Population Health Survey, 1994-1995. Am $\mathscr{f}$ Epidemiol 1999;150:255-62.

7 Prescott E, Osler M, Andersen PK, et al. Mortality in women and men in relation to smoking. Int $\mathcal{F}$ Epidemio 1998;27:27-32.

8 Prescott E, Bjerg AM, Andersen PK, et al. Gender difference in smoking effects on lung function and risk of hospitalization for COPD: results from a Danish longitudinal population study. Eur Respir f 1997;10:822-7.

9 American Thoracic Society. Standards for the diagnosis and care of patients with chronic obstructive pulm disease. Am f Respir Crit Care Med 1995;152:S77-121.

10 Camargo CAJ, Weiss ST, Zhang S, et al. Prospective study of body mass index, weight change, and risk of adult- onset body mass index, weight change, and risk of adult-

11 Armitage P, Berry G. Statistical methods in medical research. Oxford: Blackwell Scientific Publications, 1987:399-405.

12 Gulsvik A. Prevalence and manifestations of obstructive lung disease in the city of Oslo. Scand $\mathcal{F}$ Respir Dis 1979;60: $286-96$.

13 Lundback B, Stjernberg N, Nystrom L, et al. An interview study to estimate prevalence of asthma and chronic bronchitis. The obstructive lung disease in northern Sweden study. Eur F Epidemiol 1993;9:123-33.

14 Montnémery P, Ädelroth E, Heuman K, et al. Prevalence of obstructive lung diseases and respiratory symptoms in southern Sweden. Respir Med 1998;92:1337-45.

15 Keiding L, ed. Asthma, allergy, and other types of hypersensitivity in Denmark - and the development 1987-1994. (in Danish, summary in English). Copenhagen: DIKE, 1997. ISBN 87-89662-98-9.
16 Burney PG, Luczynska C, Chinn S, et al. The European Community Respiratory Health Survey. Eur Respir 71994 ; 7:954-60.

17 Lundback B, Nystrom L, Rosenhall L, et al. Obstructive lung disease in northern Sweden: respiratory symptoms assessed in a postal survey. Eur Respir f 1991;4:257-66.

18 Holmen J, Midthjell K, Forsen L, et al. [A health survey in Nord-Trondelag 1984-86. Participation and comparison of attendants and non-attendants]. Tidsskr Nor Laegeforen 1990;110:1973-7.

19 Chinn S, Burney PG. On measuring repeatability of data rom self-administered questionnaires. Int 7 Epidemiol 1987;16:121-7.

20 Bakke P, Gulsvik A, Lilleng P, et al. Postal survey on airborne occupational exposure and respiratory disorders in Norway: causes and consequences of non-response. $\mathcal{F}$ Epidemiol Community Health 1990;44:316-20.

21 Vestbo J, Rasmussen FV. Baseline characteristics are not sufficient indicators of non-response bias follow up studies. f Epidemiol Community Health 1992;46:617-19.

22 Anthonisen NR. Epidemiology and the Lung Health Study. Eur Respir Rev 1997;7:202-5.

23 Ronmark E, Lundback B, Jonsson E, et al. Incidence of asthma in adults-report from the Obstructive Lung Disease in Northern Sweden Study. Allergy 1997;52:1071-

24 Brown CA, Crombie IK, Smith WC, et al. The impact of quitting smoking on symptoms of chronic bronchitis: results of the Scottish Heart Health Study. $f$ Epidemiol Community Health 1991;46:112-16.

25 Freund KM, Belanger AJ, D'Agostino RB, et al. The health risks of smoking. The Framingham Study: 34 years of follow-up. Ann Epidemiol 1993;3:417-24.

26 Gulsvik A. Prevalence of respiratory symptoms in the city of Oslo. Scand F Respir Dis 1979;60:275-85.

27 Mossey JM, Shapiro E. Self-rated health: a predictor of mortality among the elderly. Am $\mathcal{F}$ Public Health 1982;72: $800-8$

28 Carpenter L, Beral V, Strachan D, et al. Respiratory symptoms as predictors of 27 year mortality in a representative sample of British adults. BMf 1989;299:357-61.

29 Key TJ, Pike MC, Baron JA, et al. Cigarette smoking and steroid hormones in women. I Steroid Biochem Mol Biol 1991;39:529-34.

30 Janson C, Chinn S, Jarvis D, et al. Physician-diagnosed asthma and drug utilization in the European Community Respiratory Health Survey. Eur Respir f 1997;10:1795802 .

31 Bakke P, Gulsvik A. [Allergic diseases in Norway. Operative definition, occurrence and risk factors]. Nord Med 1992; 107:108-9, 111

32 Pallasaho P, Lundback B, Laspa SL, et al. Increasing prevalence of asthma but not of chronic bronchitis in Finland? Report from the FinEsS-Helsinki Study. Respir Med 1999; 93:798-809.

33 Magnus P, Jaakkola JJ. Secular trend in the occurrence of asthma among children and young adults: critical appraisal ( of repeated cross sectional surveys. BMf 1997;314:1795-9. asthma in the elderly. Eur Respir f 1998;12:564-8.

35 Parameswaran K, Hildreth AJ, Chadha D, et al. Asthma in the elderly: underperceived, underdiagnosed and undertreated; a community survey. Respir Med 1998;92: 573-7.

36 WHO. Tobacco or health: a global status report. Geneva: WHO, 1998.

37 Waldron I. Patterns and causes of gender differences in smoking. Soc Sci Med 1991;32:989-1005.

38 Moffatt RJ, Owens SG. Cessation from cigarette smoking: changes in body weight, body composition, resting metabolism, and energy consumption. Metabolism 1991;40: 465-70.

39 Williamson DF, Madans J, Anda RF, et al. Smoking cessation and severity of weight gain in a national cohort. $N$ Engl f Med 1991;324:739-45.

40 Flodin U, Jonsson P, Ziegler J, et al. An epidemiologic study of bronchial asthma and smoking. Epidemiology 1995;6: 503-5.

41 Vesterinen E, Kaprio J, Koskenvuo M. Prospective study of asthma in relation to smoking habits among 14,729 adults. Thorax 1988;43:534-9.

42 Becklake MR, Lalloo U. The "healthy smoker": a phenomenon of health selection? Respiration 1990;57:137-44.

43 Dodge R, Cline MG, Burrows B. Comparisons of asthma emphysema, and chronic bronchitis diagnoses in a genera population sample. Am Rev Respir Dis 1986;133:981-6.

44 Amos A. Women and smoking. Br Med Bull 1996;52:74-89. 